\title{
Ku70 N-terminal lysines acetylation/deacetylation is required for radiation- induced DNA-double strand breaks repair
}

\author{
A. AL EMAM ${ }^{1,2,3, *}$, D. ARBON ${ }^{3}$, M. JEEVES ${ }^{3}$, B. KYSELA ${ }^{3, *}$ \\ ${ }^{1}$ Pathology Department, College of Medicine, King Khalid University, Abha, KSA; ${ }^{2}$ Forensic Medicine and Clinical Toxicology Department, \\ Mansoura University, Egypt; ${ }^{3}$ Institute of Cancer and Genomic Sciences, School of Medicine and Dentistry, University of Birmingham, B15 2TT, \\ UK
}

*Correspondence: b.kysela@bham.ac.uk; alemam.ahmed@gmail.com

Received October 20, 2017 / Accepted February 1, 2018

\begin{abstract}
Ku70 protein in hetero-trimeric complex with Ku80 and DNA-dependent protein kinase catalytic subunit (DNA-PKcs) is a critical component in nonhomologous-end-joining (NHEJ), the major machinery of DSBs repair in mammalian cells. It has been previously shown that modulation of Ku70 acetylation by histone deacetylases (HDAC) inhibitors induced sensitization of cancer cells to chemotherapeutic agents. However, the effects of this modulation on the repair of Ionizing Radiation (IR)-induced DSBs and the importance of dynamic equilibrium of acetylation/deacetylation have not been studied in detail. To address these questions, aceto-blocking and aceto-mimicking mutants were designed by replacing Ku70 lysine residues K317, K331 and K338 with arginine and glutamine respectively via site-directed mutagenesis. Transformed human embryonic lung fibroblasts MRC5VA were transfected to create stables cells lines over-expressing Ku70 mutant proteins. Clonogenic survival and $\gamma-\mathrm{H} 2 \mathrm{AX}$ foci assays were then performed to study the impact of these mutants on DNA repair proficiency of MRC5VA cells in response to IR. We report here that both Ku70 aceto-blocking and aceto-mimicking mutants rendered MRC5VA cells more susceptible to IR in terms of clonogenic survival and $\gamma \mathrm{H} 2 \mathrm{AX}$ foci. Moreover, modeling the possible interactions and structural impact of these aceto-blocking and aceto-mimicking mutants with DNA substrate showed that mimicking acetylation/deacetylation of K331 and K338 could directly compromise KU-DNA interactions, whereas K317 may have a more subtle role by forming a salt bridge with E330 thus optimising the positioning of the helix containing both $\mathrm{K} 331$ and K338 residues on the DNA. Our data indicates that dynamic equilibrium of acetylation/deacetylation of Ku70 lysine residues K317, K331 and K338 is critical for optimal repair of IR-induced DSBs and may offer a novel therapeutic approach for cancer treatment.
\end{abstract}

Key words: Ku70, acetylation, deacetylation, ionizing radiation, DSBs repair

$\mathrm{Ku} 70$ is a multifunctional protein that orchestrates both DNA repair and apoptosis in response to cellular stress [1-4]. Eight identified Ku70 lysine residues can undergo acetylation by either CREB-binding protein CBP or P300/ CBP-associated factor pCAF: five in its C-terminus (K539, K542, K544, K553 and K556) and three in its N-terminal DNA binding domain (K317, K331 and K338). The acetylation of K539 and K542 has been found to be critical for the regulation of $\mathrm{BAX}$-mediated apoptosis. Interestingly, while the Ku70 N-terminal K317, K331 and K338 have been suggested to play a role in DNA repair, this role has not been fully investigated [5]. In theory, the dual role of Ku70 may be regulated at both transcriptional and post-translational levels and targeted acetylation and deacetylation by histone acetyltransferases (HATs) and HDACs is likely to play a role in this regulation. Post-translational regulation, however, is a more likely candidate because the KU complex is one of the most abundant protein complexes in human cells and it either has no components or components are only very mildly up-regulated in response to DNA damaging stimuli. Moreover, increased Ku70 acetylation as a result of generic HDAC inhibition has been shown to abolish its ability to bind Bcl-2-associated $\mathrm{X}$ protein (BAX) and suppress BAX-mediated apoptosis [5-7].

The traditional view is that dynamic cooperation between HDACs and HATs regulates gene transcription by chromatin modifications and their imbalance can lead to carcinogenesis [8,9]. Nevertheless, several studies highlighted the varied mechanisms of action of HDAC inhibitors at both the epigenetic and non-epigenetic levels. HDAC inhibitors can 
also act as an adjuvant to radio-/chemotherapy via various, (often not well defined) mechanisms that include the acetylation of both histones [10], and non-histone proteins [11, 12], affecting cell proliferation and survival. In a recent study Chen and colleagues reported that HDAC inhibitors increased Ku70 acetylation. Although this increased acetylation of Ku70 did not affect its complex formation with Ku80, it was proposed that the chemosensitizing effect of HDAC inhibitors could be attributed to their ability to suppress DSBs repair [13].

KU heterodimer interacts with DNA through electrostatic interactions between its positively charged residues and the sugar phosphate backbone of DNA [14, 15]. Chen and colleagues tested the assumption that acetylation of lysine residues K317, K331 and K338 in the ring region would diminish the DNA-binding activity of Ku70. They found that constitutive acetylation at K338 reduces the DNA-binding activity, whereas substitution of K317 or K331 with glutamine has no significant effect. This study highlighted the possibility that acetylation/deacetylation of Ku70 N-terminal lysines has a more general role in DNA damage responses to IR. Radiotherapy alone has become increasingly used as a definitive modality for cancer. However, the increased toxicity due to bone marrow suppression and normal tissue damage highlights the need for more precisely targeted therapy. Indeed, combining radiotherapy with chemotherapy or molecularly targeted therapies has improved the outcome of various cancers $[16,17]$. Therefore, we decided to study the effects of acetylation/deacetylation of Ku70 lysine residues $\mathrm{K} 317, \mathrm{~K} 331$ and $\mathrm{K} 338$ in response to IR in a systematic way in vivo. It is hoped that these studies will contribute to a more complete rationale for designing new cancer treatment strategies using different combinations of chemotherapy, radiotherapy and acetylation/deacetylation modulators to achieve optimal therapeutic benefits.

\section{Materials and methods}

Preparation of the wild type constructs. First-strand cDNA was synthesized using Thermoscript Reverse Transcriptase (Invitrogen). Proofreading PCRs using primers (available on request) with end-incorporated restriction sites, (NotI and BamHI restriction sites for Ku70 and BamHI and HindIII restriction sites for Ku80) were set to amplify Ku70 and Ku 80 wild type cDNA. The PCR products corresponding to $\mathrm{Ku} 70$ and $\mathrm{Ku} 80$ (2kb and $2.2 \mathrm{~kb}$ respectively) were gel purified and cloned into pGEM-T-Easy, transformed into E. coli, and minipreped. The minipreps were sequenced to verify the wild type sequence. Ku70 cDNA was double digested with NotI and BamHI restriction endonucleases, while HindIII and BamHI were used for double digestion of Ku 80 cDNA to subclone Ku70 and Ku80 wild type cDNAs in frame into pFlag-CMV-4 vector, transformed into E. coli and minipreped. The minipreps were double digested with the same enzymes to check for the presence of the inserts.
Site-directed mutagenesis (SDM). To change each of Ku70 lysine residues K317, K331 and K338 to arginine or glutamine, two complementary primers containing the desired mutation in the middle of the primer (available on request) were designed. The QuickChange II XL SiteDirected Mutagenesis Kit (Stratagene) was used according to the manufacturer guidelines. Minipreps of the selected clones were sequenced to verify that the insert of interest contained the desired mutation. The inserts containing the desired mutation were re-ligated into freshly gel purified pFlagCMV-4 plasmid to avoid the effect of any possible changes in the vector backbone that could have been introduced during the SDM PCR. The ligation products were re-transformed, minipreped and double digested to verify the presence of the correct inserts.

Stably transfected cell lines. Embryonic human lung fibroblast cell line (MRC5VA) was transfected with pFlagKu70/wt, pFlag-Ku80 /wt and pFlag-Ku70 mutants (pFlagKu70-K317R, pFlag-Ku70-K331R, pFlag-Ku70-K338R, pFlag-Ku70-K317Q, pFlag-Ku70-K331Q and pFlag-Ku70K338Q) using FuGENE HD according to the manufacturer instructions (Roche). On the day of transfection cells were $60-70 \%$ confluent, maintained in Dulbecco's modified Eagle's Medium (DMEM), 1000mg/L glucose, supplemented with $10 \%(\mathrm{v} / \mathrm{v})$ foetal bovine serum (FBS), $2 \mathrm{mM}$ L-glutamine, $5 \%$ non-essential amino acids, $5 \%$ sodium pyruvate and 100 units/ml penicillin. The $200 \mu \mathrm{l}$ of FuGENE-DNA mixture was added drop-wise to each well in a six-well plate and the cells were then incubated at $37^{\circ} \mathrm{C}$ for 48 hours. After 48 hours, the media was aspirated and replaced with G418-supplemented complete DMEM allowing the selection of stably transfected cells. After 24 hours the cells were trypsinized and reseeded into $10 \mathrm{ml}$ tissue culture treated petri dishes and kept with frequent media changes for 2-3 weeks to allow stably transfected colonies to grow. Stable colonies were amplified and kept in G418-supplemented complete DMEM to maintain a stably transfected population.

Clonogenic survival assays. MRC5VA, pFlag-Ku70/ wt, pFlag-Ku80/wt and Empty-pFlag expressing cell lines, as control cell lines, and stable cell lines over-expressing pFlag-Ku70 mutants were grown in $75 \mathrm{~cm}^{2}$ cell culture flasks until approximately $70 \%$ confluence, trypsinised and counted by haemocytometer and serially diluted into $10 \mathrm{ml}$ universals. Cells were irradiated with 2, 4, 6 and 8Gy of IR (Caesium ${ }^{137}$ source), with un-irradiated controls treated in an identical way. Cells were seeded out at 50, 100, 500, 1,000, 5,000 and 10,000 cells per well into a 6 -well plate for 0,2 , 4 and 6Gy exposures. For 8Gy exposures 500, 1,000, 5,000, $10,000,50,000$ and 100,000 cells were seeded out. The 6-well plates were incubated under standard growth conditions for approximately 2 weeks and stained with crystal violet ( $0.4 \%$ crystal violet, $50 \%$ methanol). Colonies that contained between 50 and 100 cells were counted. Each experiment was repeated in triplicate and the data statistically analysed using the Students' two-tailed t-test. 
Immunofluorescence analysis. For $\gamma \mathrm{H} 2 \mathrm{AX}$ staining, MRC5VA, pFlag-Ku70/wt, pFlag-Ku80/wt and EmptypFlag expressing cell lines (as controls) and stable cell lines over-expressing pFlag-Ku70 mutants were grown in 6-well plates containing a $22 \times 22 \mathrm{~mm}$ glass coverslip (VWR) and sterilized under UV light for 30 minutes. At the point of fixation, the media was aspirated and the coverslips were washed with PBS. $1 \mathrm{ml}$ of immunofluorescence lysis buffer was added to each coverslip (10 mM PIPES pH 6.8, $300 \mathrm{mM}$ sucrose, $20 \mathrm{mM} \mathrm{NaCl}, 3 \mathrm{mM} \mathrm{MgCl}, 0.5 \%$ Triton X-100) and incubated on ice for 7 minutes. The slides were washed in PBS and $1 \mathrm{ml}$ of $4 \%$ paraformaldehyde (diluted in PBS) was added and left on ice for 10 minutes. The fixed cells were washed 3 times with PBS. For the purpose of pFlag immunoflourescence staining, cell permeabilization buffer (20 mM Hepes pH 7.4, 50 mM NaCl, 3 mM MgCl, $300 \mathrm{mM}$ Sucrose, $0.5 \%$ Triton $\mathrm{X}-100$ ) was used for 5 minutes at $4{ }^{\circ} \mathrm{C}$ after paraformaldehyde fixation to ensure cells permeability. $10 \%$ FBS was then added to the slides and incubated on a rocking platform for 1 hour at room temperature to block non-specific proteins. The FBS was removed, the slides were washed with PBS and $100 \mu \mathrm{PBS}$ supplemented with $2 \%$ FBS and primary antibody Anti-pFlag (Sigma) was added and incubated at $37^{\circ} \mathrm{C}$ for 1 hour on a rocking platform. The coverslips were washed 3 times, 5 minutes each, with PBS. Then, $100 \mu \mathrm{l}$ PBS supplemented with $2 \%$ FBS and a fluorescently tagged secondary antibody AlexaFluor 594 (Invitrogen) was added and incubated at $37^{\circ} \mathrm{C}$ for 1 hour in the dark on a rocking platform. The coverslips were again washed 3 times, 5 minutes each, with PBS in the dark. The coverslips were mounted with Vectashield (Vector Laboratories) mounting media, containing 4, 6-diamidino-2phenylindole (DAPI), onto microscope slides (VWR). Slides were analysed with a Carl Zeiss microscope using a $100 \times$ objective and Smart Capture2 software.

$\gamma \mathbf{H}$ 2AX quantification. The four control cell lines and the six stable cell lines over-expressing pFlag-Ku70 mutants were grown on coverslips in 6-well dishes. Cells were irradiated with 5Gy of IR and placed in the incubator. The cells were fixed 30 minutes and 24 hours post-irradiation and incubated with anti- $\gamma \mathrm{H} 2 \mathrm{AX}$ primary antibody (Upstate) and then with the secondary fluorescent antibody, AlexaFluor 594 (Invitrogen). After mounting and visualization as described in the previous paragraph, a minimum of 100 nuclei per-timepoint-per-sample were examined and $\gamma \mathrm{H} 2 \mathrm{AX}$ foci per nucleus were counted using Photoshop Software (Adobe). The experiment was repeated twice and the data was statistically analysed using the Students' two-tailed t-test.

Western blotting. When cells reached $90 \%$ confluence they were trypsinised, washed in PBS and centrifuged. The cell pellets were resuspended in twice the volume of RIPA buffer (50 mM Tris- $\mathrm{HCl}$ pH 7.5, 1 mM EDTA, $150 \mathrm{mM} \mathrm{NaCl}$, $0.1 \%$ SDS, $0.5 \%$ deoxycholic acid, $1 \%$ Igepal CA-360 (Sigma) with $10 \%$ protease inhibitor (Roche) and placed on ice for 20 minutes. The suspension was clarified by centrifugation and the protein concentration determined by Bradford assay. An aliquot of $15 \mu \mathrm{g}$ of each protein sample was then diluted with 5 times the loading buffer $(65 \mathrm{mM}$ Tris- $\mathrm{HCl}, \mathrm{pH} 8.0$, $10 \%(\mathrm{v} / \mathrm{v})$ Glycerol, 2.3\% (w/v) SDS, 0.01 Bromophenol blue, $1 \%$ DTT), denatured at $100^{\circ} \mathrm{C}$ for 5 minutes and placed immediately on ice. The samples, including a protein standard (Sigma), were resolved by SDS-PAGE and transferred onto a Polyvinylidene Fluoride Membrane (PVDF) (Millipore) in CAPS buffer (10 mM CAPS (Sigma), 10\% methanol). The membrane was subsequently blocked using $5 \mathrm{ml}$ of $5 \%$ non-fat milk in PBS $+0.1 \%$ Tween overnight at $4{ }^{\circ} \mathrm{C}$ with agitation in order to reduce non-specific immunoglobulin binding. The PVDF membrane was placed in a $50 \mathrm{ml}$ centrifuge tube (Falcon), with the protein bound side of the membrane facing inwards, containing $5 \mathrm{ml}$ of $5 \%$ non-fat milk in PBS $+0.1 \%$ Tween and the primary antibody Anti-pFlag (Sigma) diluted to $1 / 1000$. The centrifuge tube was placed on a tube roller and incubated at room temperature for 1 hour and the membrane was then removed from the centrifuge tube and placed face upwards in a container containing PBS $+0.1 \%$ Tween and placed on a rotating tray for 5 minutes. This was repeated twice with fresh PBS $+0.1 \%$ Tween. The membrane was again put in another $50 \mathrm{ml}$ centrifuge tube containing $5 \mathrm{ml}$ of $5 \%$ non-fat milk protein in PBS $+0.1 \%$ Tween and the secondary rabbit antimouse-HRP antibody (Dako) diluted at 1/1000 and placed on a tube roller and incubated at room temperature for 1 hour. The membrane was removed from the centrifuge tube and washed three times, 5 minutes each time, in PBS $+0.1 \%$ Tween. Bound antibody was detected by enhanced chemiluminescence detection kit (Amersham).

Structure-function modeling. Modeling was performed with PyMOL [18], and the pdb KU heterodimer structure bound to DNA (1JEY) was used as template [14]. Mutants were simulated in PyMOL and the rotamer with the least energy was chosen for depiction. Ionic interactions were predicted based on inter-atom distances.

\section{Results}

Transfection constructs. The wild type cDNAs of both Ku70 and Ku80 were amplified by proofreading PCRs cloned in pGEM-T-Easy vector and transformed to E. coli. The positive clones containing the expected size of $\mathrm{Ku} 70$ and Ku80 inserts were sequenced, and the two verified clones each containing the wild type sequence of both Ku70 and Ku80 were subcloned into pFlag vector. The pFlag-Ku 70/wt cDNA was used as a template for SDM PCRs to change Ku70 lysine residues $\mathrm{K} 317$, $\mathrm{K} 331$ and $\mathrm{K} 338$ to either arginine or glutamine. Replacement of lysine was with arginine mimics deacetylation and replacement of lysine was with glutamine mimics acetylation [5, 19]. All the subcloned SDM PCR products were verified by sequencing to check that the desired mutations were incorporated in the right position and that the inserts were still in frame (Figure 1). 

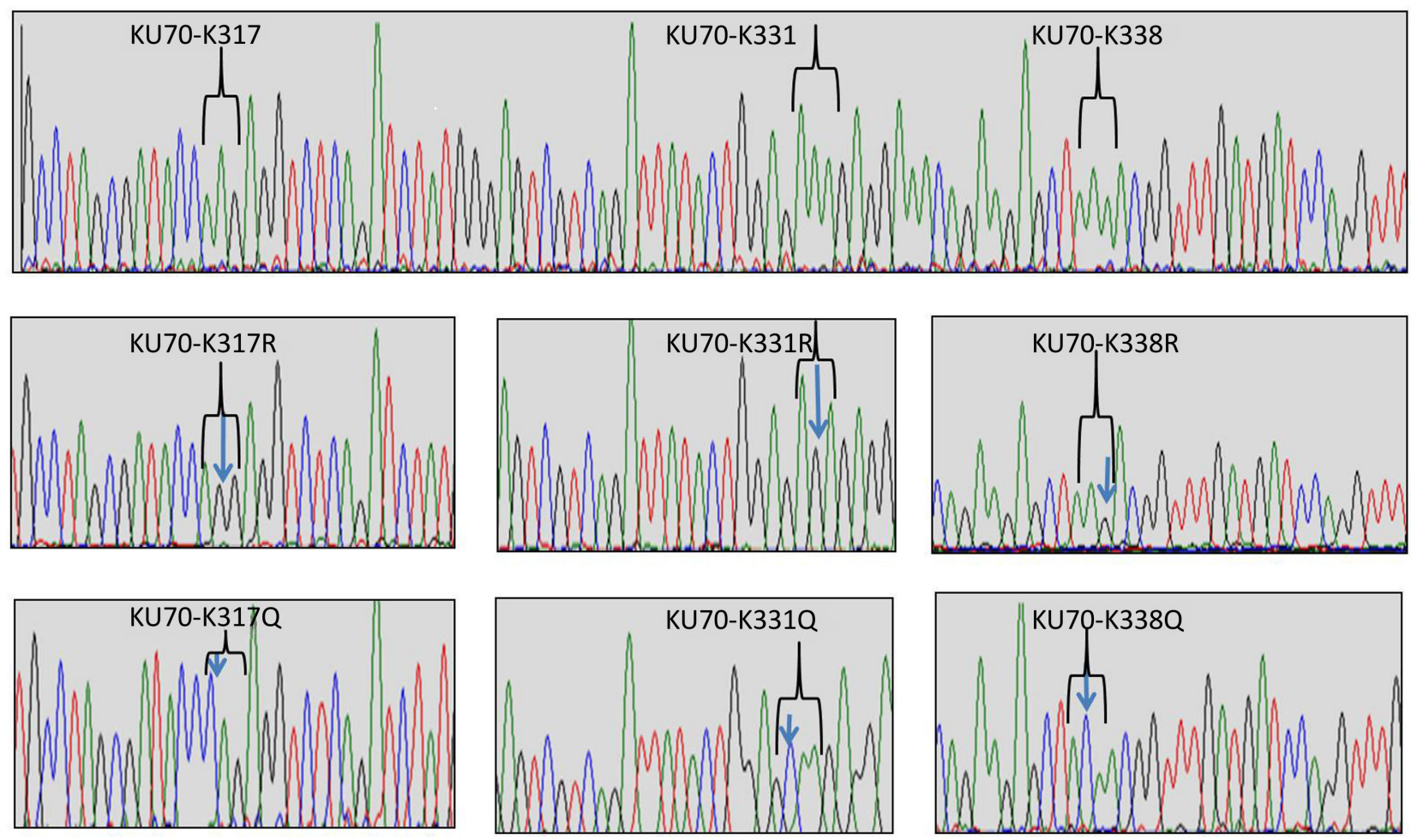

Figure 1. Sequence chromatograms of pFlag-Ku70/wt and pFlag-Ku70 mutant constructs. Firstly, Ku70 and Ku80 wild type cDNAs were synthesized using Thermoscript Reverse Transcriptase (Invitrogen). Secondly, the QuickChange II XL Site-Directed Mutagenesis Kit (Stratagene) was used to replace each of Ku70 lysine residues K317, K331 and K338 to arginine or glutamine by two complementary primers containing the desired mutation in the middle of each primer pairs. Then, the sequence of all the constructs (wild types and mutants) was checked with Dye terminator sequencing. The top chromatogram is part of Ku70/wt sequence showing the three lysine residues: K317, K331 and K338. The middle panel represents three partial sequences showing the pFlag-Ku70 aceto-blocking mutants: Ku70-K317R, Ku70-K331R and Ku70-K338R and the mutated bases are indicated by blue arrows. The bottom panel represents three partial sequences showing the pFlag-Ku70 aceto-mimicking mutants: Ku70-K317Q, Ku70-K331Q and Ku70-K338Q and the mutated bases are indicated by blue arrows.

Establishing stable cell lines overexpressing pFlagKu70/wt, pFlag-Ku80/wt and pFlag-Ku70 mutants. Using Fugene HD transfection reagents, the following constructed plasmids were transfected into MRC5VA cells to create stable cell lines over-expressing pFlag-Ku70/wt, pFlag-Ku80/wt and pFlag-Ku70 aceto-blocking and aceto-mimicking mutant proteins. These plasmids were; pFlag-Ku70/wt, pFlag-Ku80/ wt, pFlag-Ku70 aceto-blocking mutants (pFlag-Ku70K317R, pFlag-Ku70-K331R and pFlag-Ku70-K338R) and pFlag-Ku70 aceto-mimicking mutants (pFlag-Ku70-K317Q, pFlag-Ku70-K331Q and pFlag-Ku70-K338Q).

Figure 2 shows the harvested cells and protein extracts used to check the expression of individual aceto-blocking and aceto-mimicking mutant proteins by Western blot. Positive clones expressing the mutant and the wild type proteins were then selected for the further analysis.

Expression and cellular localization of the pFlag-Ku70 mutants. Immunofluorescence analysis was performed on all pFlag-Ku70 aceto-blocking mutants and pFlag-Ku70 acetomimicking mutants in order to verify the correct nuclear localisation of the over-expressed protein constructs. Here, pFlag-Ku70/wt was the positive control and MRC5VA the negative control. Figure 3 shows that all the mutants behaved similarly to the pFlag-Ku70/wt positive control and that they were exclusively localized in the nucleus.

Clonogenic survival assay. All the aceto-blocking, aceto-mimicking mutant cell lines and the four control cells were exposed to increasing doses of IR and their survival rates were plotted (Figure 4). This enabled assessment of the effects of pFlag-Ku70 aceto-blocking and pFlag-Ku70 aceto-mimicking mutants on cell survival following exposure to IR. The aceto-blocking and acetomimicking mutant cell lines were found to be more radiosensitive than the four control cell lines. At $6 \mathrm{~Gy}$ and $8 \mathrm{~Gy}$, the differences between the surviving fractions of both aceto-blocking and aceto-mimicking mutant cell lines and that of the four control cell lines were statistically significant with p-values: $\mathrm{p}<0.05$.

$\gamma \mathrm{H} 2 \mathrm{AX}$ DNA repair foci assay. $\gamma \mathrm{H} 2 \mathrm{AX}$ is an extremely sensitive and early marker of DSBs which can sense low levels of DNA damage much better than other methods [20-22], and reports confirm that it can detect doses of radiation down to $1 \mathrm{mGy}$ [23]. Residual $\gamma \mathrm{H} 2 \mathrm{AX}$ can reflect either cell radio-sensitivity or their repair efficiency [24]. 

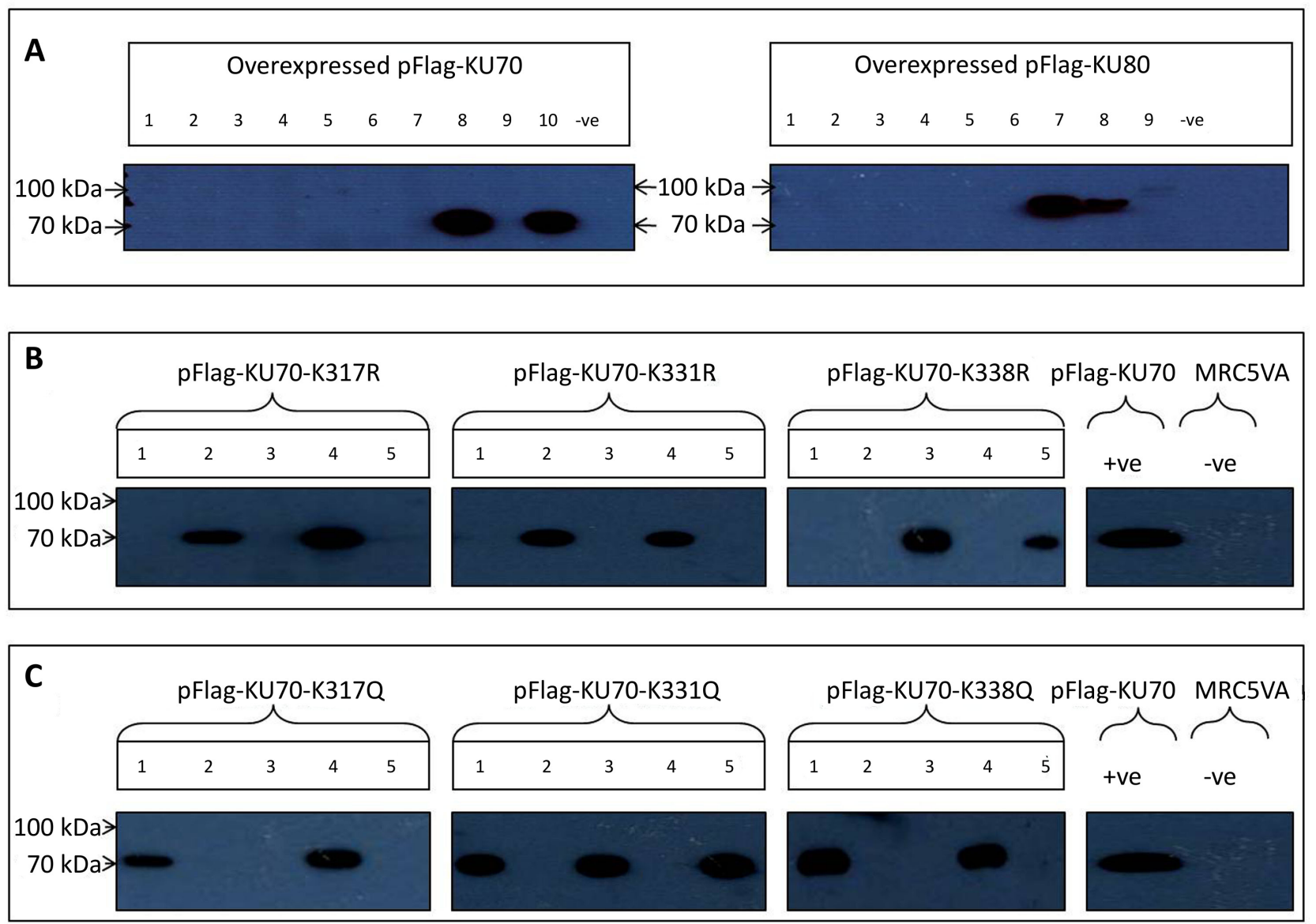

Figure 2. Overexpression of pFlag-Ku70/wt, pFlag-Ku80/wt and pFLag-Ku70 mutants. The expression status of all the stably transfected cell lines was checked with Western blot. Panel A) Western blots show the over-expression of pFlag-Ku70/wt transfected cell line on the left side ( 2 clones were over-expressing, lanes 8 and 10) and pFlag-Ku80/wt transfected cell line on the right side (2 clones were over-expressing, lanes 7 and 8 ) alongside MRC5VA as a negative control. Panel B) shows 3 Western blots (from left to right) for pFlag-Ku70-K317R, pFlag-Ku70-K331R and pFlag-Ku70-K338R transfected cell lines along MRC5VA as a negative control and pFlag-KU70/wt as a positive control. The Western blots for both pFlag-Ku70-K317R and pFlag-Ku70-K331R transfected cell lines show 2 over-expressing clones (lanes 2 and 4 ). The Western blot for pFlag-Ku70-K338R transfected cell line shows 2 over-expressing clones (lanes 3 and 5). Panel C) shows 3 Western blots (from left to right) for pFlag-Ku70-K317Q, pFlag-Ku70-K331Q and pFlag-Ku70-K338Q transfected cell lines along MRC5VA as a negative control and pFlag-Ku70/wt as a positive control. The Western blot for both pFlag-Ku70-K317Q and pFlag-Ku70-K338Q transfected cell lines show 2 over-expressing clones (lanes 1 and 4). The Western blot for pFlag-Ku70K331Q transfected cell line shows 3 over-expressing clones (lanes 1, 3 and 5).

The $\gamma \mathrm{H} 2 \mathrm{AX}$ assay has therefore become the most popular technique for detecting DSBs. Clonogenic survival assays revealed that all the mutant cells were more radiosensitive than control cells. In order to determine the effects of pFlag-Ku70 aceto-blocking and aceto-mimicking mutants on DSB repair, the levels of $\gamma \mathrm{H} 2 \mathrm{AX}$ foci were studied in both the aceto-blocking and aceto-mimicking mutant cell lines and the four control cell lines after exposure to 5Gy IR. The $\gamma \mathrm{H} 2 \mathrm{AX}$ foci were then quantified in un-irradiated cells to determine the background level 30 minutes after IR in order to determine peak DNA damage, and also 24 hours post-irradiation which is the time-limit when the majority of DSBs should be normally repaired. Figure 5 shows the foci in the aceto-blocking and aceto-mimicking mutant cell lines and the four control cells (un-irradiated
30 minutes and 24 hours post-irradiation). All the acetoblocking, aceto-mimicking mutant cell lines and the control cell lines had an average of four foci per nucleus as a basal background in non-irradiated cells. At 30 minutes post IR, all the mutants and control cell lines displayed comparably high amounts of $\gamma \mathrm{H} 2 \mathrm{AX}$ foci, with an average of 50 large foci per nucleus. Twenty four hours post-irradiation, the majority, if not all, of the $\gamma \mathrm{H} 2 \mathrm{AX}$ foci disappeared in the control cell lines, with eight foci on average per nucleus. The aceto-blocking and aceto-mimicking mutant cell lines retained a higher amount of $\gamma \mathrm{H} 2 \mathrm{AX}$ foci after 24 hours, 16 foci per nucleus on average.

Plotting the number of un-repaired breaks as a percentage of the total breaks seen at 30 minutes, termed the residual foci, clearly highlighted the difference between the aceto- 


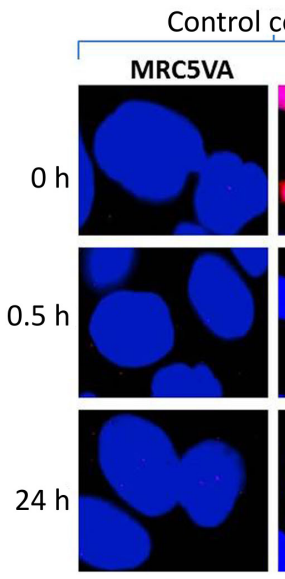

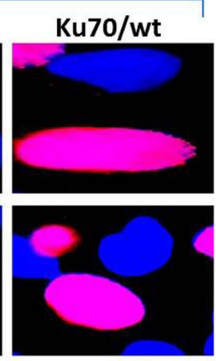

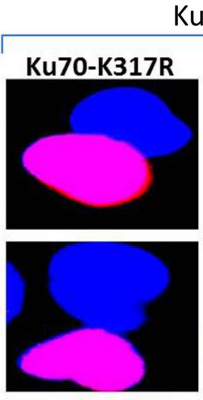

Ku70Lys<Arg Mutants

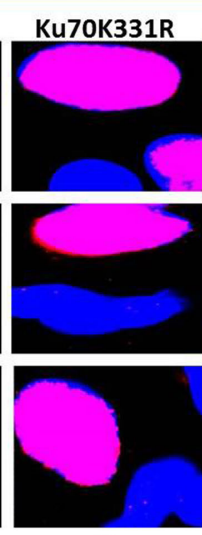

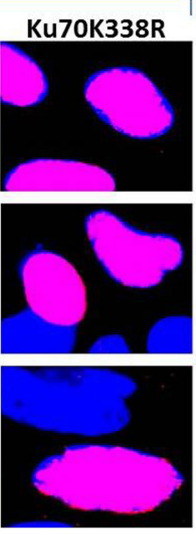

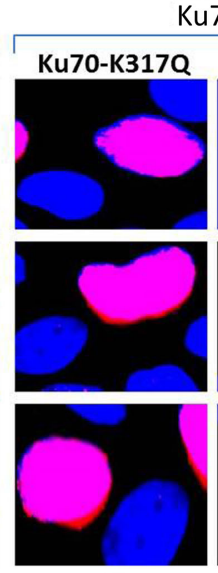

Ku70Lys<Glu Mutants

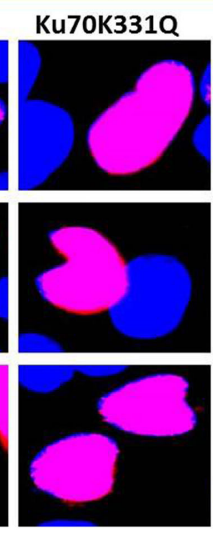

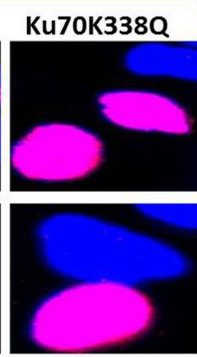

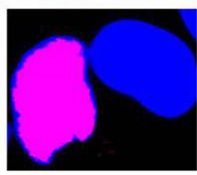

Figure 3. Expression and cellular localization of pFlag-Ku70 mutants. The expression of pFlag-Ku70/wt, pFlag-Ku70 aceto-blocking and aceto-mimicking mutant cell lines was checked with immunofluorescence using primary pFlag and secondary fluorescent antibody. Immunofluorescence shows nuclear red staining of pFlag-Ku70 aceto-blocking mutants pFlag-Ku70-K317R, pFlag-Ku70-K331R and pFlag-Ku70-K338R (lanes 3, 4 and 5 respectively) and aceto-mimicking mutants pFlag-Ku70-K317Q, pFlag-Ku70-K331Q and pFlag-Ku70-K338Q (lanes 6, 7 and 8 respectively) cell lines along both pFlag-Ku70/wt cell line (lane 2) as the positive control and the MRC5VA cell line (lane 1) as the negative control. This indicates that both pFlag$\mathrm{Ku} 70 / \mathrm{wt}$ and mutants proteins localized to the nucleus.

blocking, aceto-mimicking mutant cell lines and the control cell lines (Figure 6). The differences between the residual foci of pFlag-Ku70 aceto-blocking and aceto-mimicking mutant cells and that of the control cell lines were statistically significant with $\mathrm{p}$-values: $\mathrm{p}<0.05$. This indicates that over-expressing each of the aceto-blocking and acetomimicking mutants compromised DSBs repair. In addition, all the cell lines expressing both the aceto-blocking and the aceto-mimicking Ku70 construct also showed a higher proportion of cells with homogenous pan-nuclear $\gamma \mathrm{H} 2 \mathrm{AX}$ staining pattern (Figure 7), and this was not detected in any of the four control cell lines. Although it was not specifically analyzed, this staining pattern provides a pre-apoptotic signal and highlights the possibility that acetylation and deacetylation of these lysine residues is important for the apoptotic function previously reported for Ku70 [5].

\section{Discussion}

In order to address the functional consequences of altering Ku70 lysine residues K317, K331 and K338, they were replaced by arginine which is charge-conserving (mimicking deacetylation), and by glutamine, which is non-charged (mimicking acetylation). After creating the wild type and mutant constructs and establishing stable cell lines over-expressing these mutant proteins, clonogenic survival assays revealed that both the acetoblocking (Figure 4A and $\mathrm{B}$ ) and the aceto-mimicking mutants (Figure 4C and D) of these three lysine residues render the cells sensitive to IR compared to the control cell lines. This effect was statistically significant at $8 \mathrm{~Gy}$ of IR. The radio-sensitizing effect was not so obvious at lower radiation doses because transfected cells retain the wild type Ku70 protein which is most likely sufficient for repair of the lower induced DNA damage, and also because the effect of the presence of the mutant proteins is only manifested at higher IR doses which cause greater DNA damage. In a similar fashion, we previously reported that lower LigaseIV (LigIV) enzymatic activity associated with LIG4 hypomorphic mutation in a patient was sufficient for dealing with the physiologically normal background levels of DSB, but the patient dramatically over-responded to radiotherapy at the onset of leukemia $[25,26]$. The correct cellular localization of all the mutant Ku70 proteins (Figure 3) also pointed to the possibility that the effect on survival is mediated by the functional defect in the handling and repairing of DSBs caused by the ionizing radiation. To evaluate the impact of both pFlag-Ku70 aceto-blocking and aceto-mimicking mutants on the efficacy of DSBs repair, the $\gamma \mathrm{H} 2 \mathrm{AX}$ foci assay was performed in both pFlagKu70 aceto-blocking and aceto-mimicking (Figure 5) mutant cell lines and control cell lines. The percentage of $\gamma \mathrm{H} 2 \mathrm{AX}$ residual foci was quantified in all the mutant cell lines in response to 5Gy IR and compared to those of the control cell lines. Both pFlag-Ku70 aceto-blocking (Figure 6A) and aceto-mimicking mutants (Figure 6B) retained statistically significant higher percentages of residual foci 24 hours post irradiation than the control cell lines. This strongly suggests that both the pFlag-Ku70 aceto-blocking and aceto-mimicking mutants compromised the efficiency of DSBs repair. Therefore, both clonogenic survival and $\gamma \mathrm{H} 2 \mathrm{AX}$ data suggest that the acetylation status of the Ku70 lysine residues K317, K331 and K338 is critical for proper function of the DNA-PK key NHEJ complex. This 

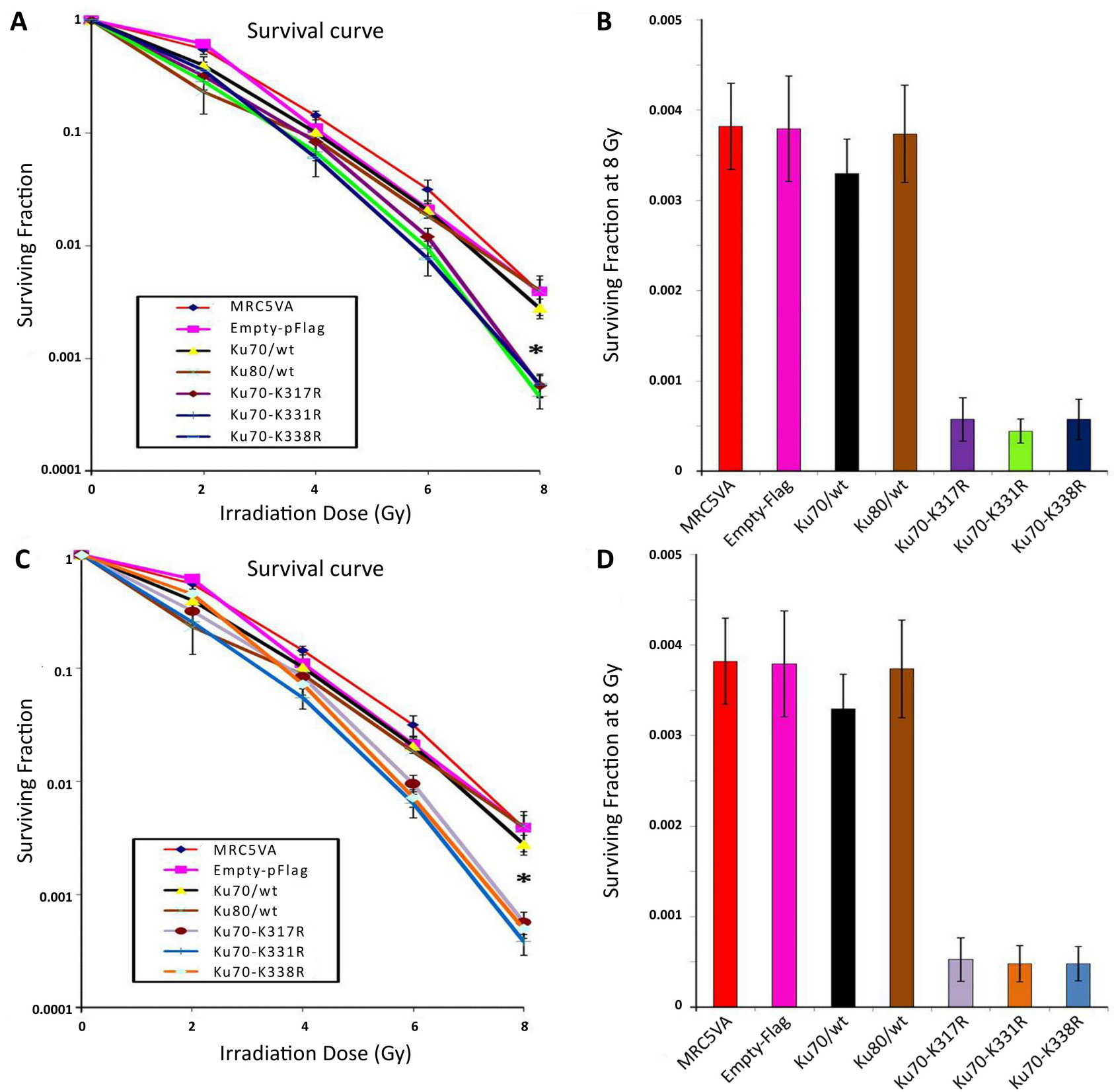

Figure 4. Clonogenic survival of pFlag-Ku70 aceto-blocking and aceto-mimicking mutants in response to IR. The effects of pFlag-Ku70 aceto-blocking and aceto-mimicking mutants on cell survival in response to Ionizing Radiation (IR) were studied by the clonogenic survival assay. The clonogenic survival curves $A$ ) show that pFlag-Ku70 aceto-blocking (pFlag-Ku70-K317R, pFlag-Ku70-K331R and pFlag-Ku70-K338R) mutant cell lines are more sensitive than the control cell lines (MRC5VA, Empty-pFlag, pFlag-Ku70/wt, and pFlag-Ku80/wt), especially at 8Gy as indicated by the black star. The bar graph B) shows that the surviving fractions of pFlag-Ku70 aceto-blocking (pFlag-Ku70-K317R, pFlag-Ku70-K331R and pFlag-Ku70-K338R) mutant cell lines are significantly lower than those of the control cell lines at $8 \mathrm{~Gy}$. The clonogenic survival curves $\mathrm{C}$ ) show that pFlag-Ku70 aceto-mimicking (pFlag-Ku70-K317Q, pFlag-Ku70-K331Q and pFlag-Ku70-K338Q) mutant cell lines are more sensitive than the control cell lines (MRC5VA, Empty-pFlag, pFlag-Ku70/wt, and pFlag-Ku80/wt), especially at 8Gy indicated by the black star. The bar graph D) shows that the surviving fractions of pFlag-Ku70 aceto-mimicking (pFlag-Ku70-K317Q, pFlag-Ku70-K331Q and pFlag-Ku70-K338Q) mutant cell lines are significantly lower than those of the control cell lines (MRC5VA, Empty-pFlag, pFlag-Ku70/wt, and pFlag-Ku80/wt) at 8Gy. The star represents the statistically significant difference of $\mathrm{p}<\mathbf{0 . 0 5}$ by Students' two tailed t-test and $\mathrm{n}=3$ independent experiments and error bars represent \pm standard error of the mean.

combined data strongly indicates that a dynamic equilibrium of the acetylation status of these three lysine residues is required for regulating DNA-PK in response to IR.
Our data contrasts with the previous study which found that mimicking acetylation of K338 suppresses DNA-binding of Ku70 and sensitizes cells to doxorubicin, but mimicking 
Control cell lines
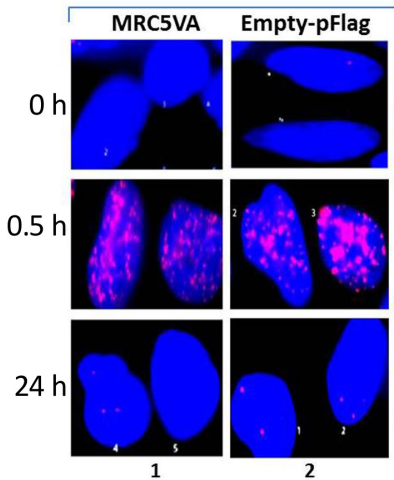
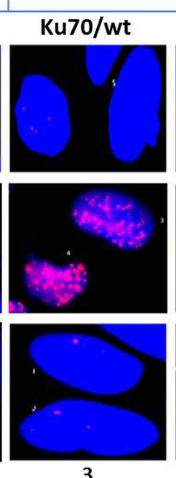
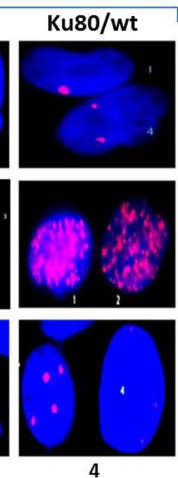

Ku70Lys<Arg Mutants
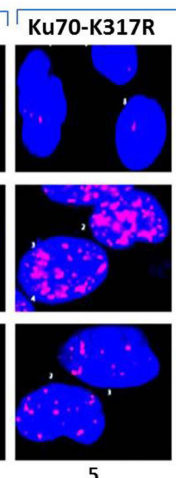
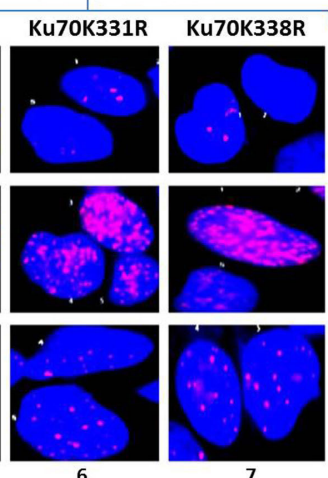
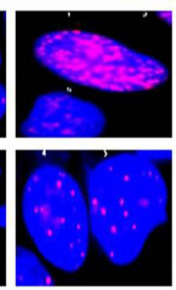

7

Ku70Lys<Glu Mutants
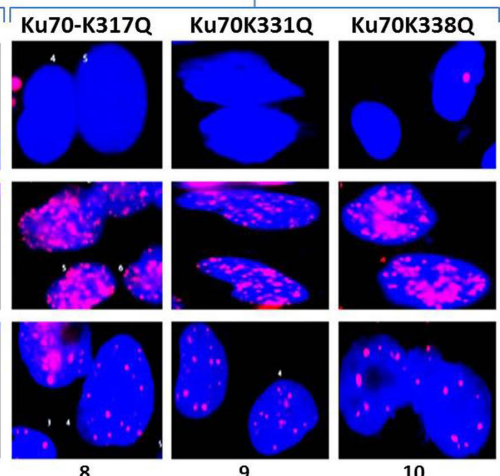

8

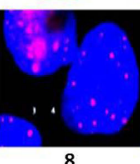

10

Figure 5. $\gamma \mathrm{H} 2 \mathrm{AX}$ foci of pFlag-Ku70 aceto-blocking and aceto-mimicking mutant cell lines. The effects of pFlag-Ku70 aceto-blocking and aceto-mimicking mutants on the DNA repair capacity were studied by $\gamma \mathrm{H} 2 \mathrm{AX}$ foci assay. All the cell lines were grown on coverslips in 6-well dishes, irradiated with $5 \mathrm{~Gy}$ and incubated. At 0 hour (un-irradiated), 30 minutes and 24 hours post-irradiation the cells were fixed, incubated with anti- $\gamma \mathrm{H} 2 \mathrm{AX}$ primary antibody (Upstate) and then followed by the secondary fluorescent antibody, AlexaFluor 594 (Invitrogen) and finally mounted and visualized by Carl Zeiss microscope with 100x objective and Smart Capture2 software. The un-irradiated (0h) control cell lines (MRC5VA, Empty-pFlag, pFlag-Ku70/wt, and pFlag-Ku80/wt; lanes 1, 2, 3 and 4 respectively) show an average of 4 foci $\gamma \mathrm{H} 2 \mathrm{AX}$ per nucleus which are representative of basal background DSBs, whereas at 30 minutes post-irradiation the same cells show the peak of $\gamma \mathrm{H} 2 \mathrm{AX}$ foci (an average of 50 large foci per nucleus) with the majority of these being repaired 24 hours post IR (with eight foci on average per nucleus). The un-irradiated mutant cells [pFlag-Ku70 aceto-blocking (pFlag-Ku70K317R, pFlag-Ku70-K331R and pFlag-Ku70-K338R; lanes 5, 6 and 7 respectively) and pFlag-Ku70 aceto-mimicking (pFlag-Ku70-K317Q, pFlag-Ku70$\mathrm{K} 331 \mathrm{Q}$ and pFlag-Ku70-K338Q; lanes 8, 9 and 10 respectively)] show very similar levels of $\gamma \mathrm{H} 2 \mathrm{AX}$ foci at 0 hour and 30 minutes post-irradiation to those of the control cell lines. However, there are considerably more foci remaining 24 hours post-irradiation (on average 16 foci per nucleus) indicating slower repair than in the control cell lines.

A

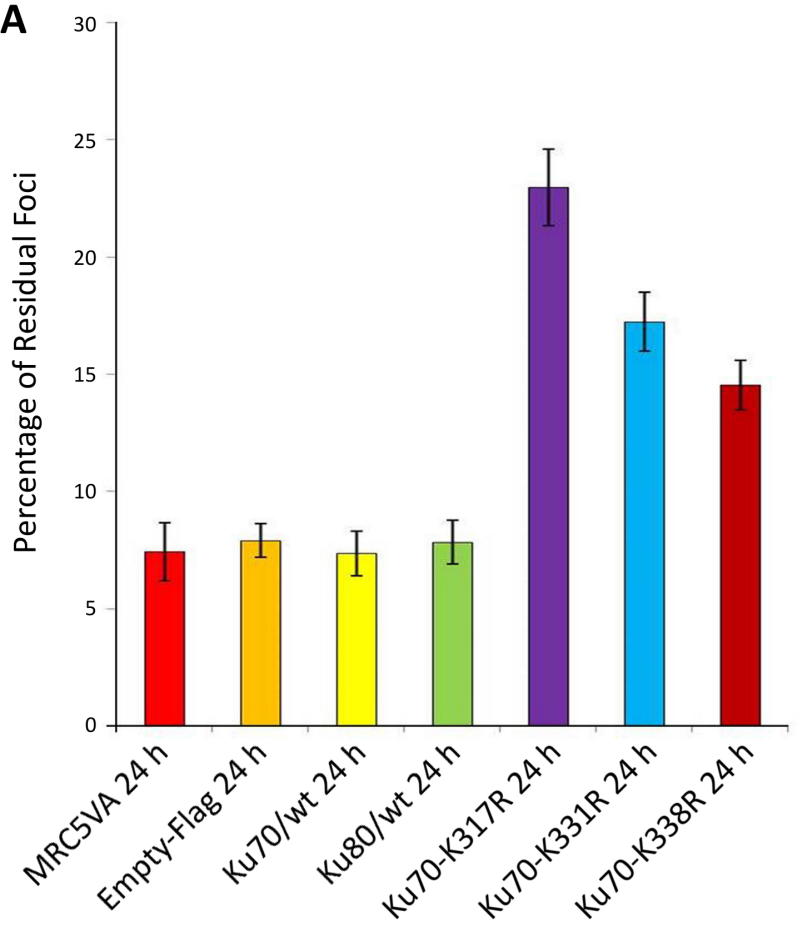

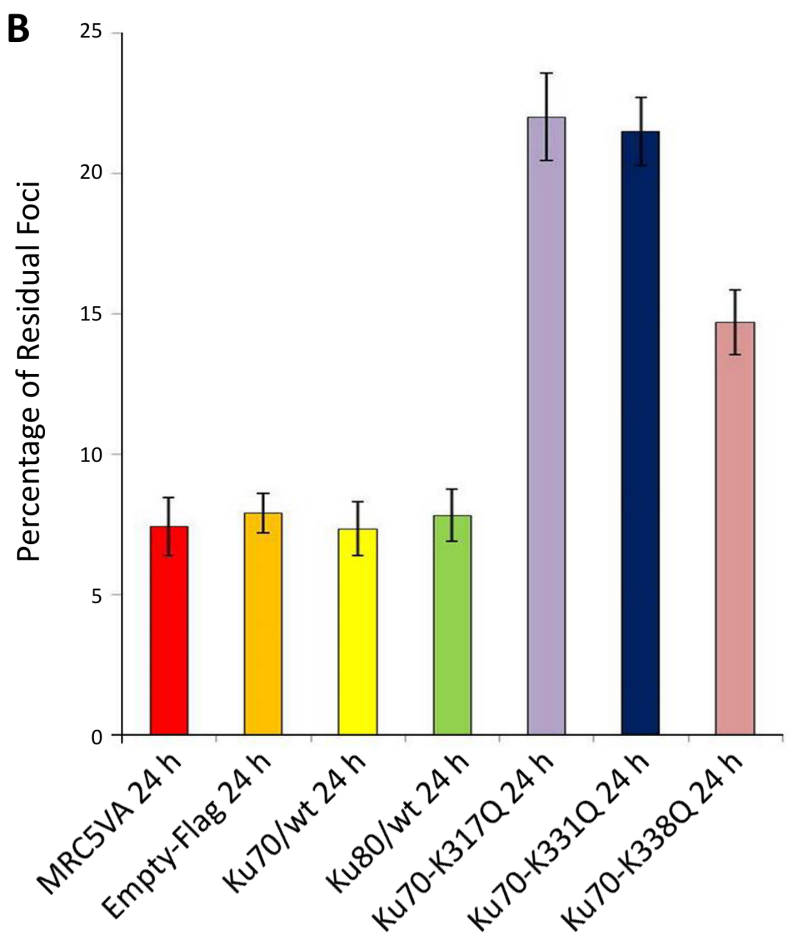

Figure 6. $\gamma \mathrm{H} 2 \mathrm{AX}$ residual foci of pFlag-Ku70 mutant cell lines 24 hours post-irradiation. After $\gamma \mathrm{H} 2 \mathrm{AX}$ foci assay of all the mutant and control cell lines were visualized by Carl Zeiss microscope with 100x objective and Smart Capture2 software, a minimum of 100 nucleus per time point per sample were examined and $\gamma \mathrm{H} 2 \mathrm{AX}$ foci per nucleus were counted using Adobe Photoshop Software. Foci counted at 30 minutes and 24 hours post-irradiation were normalised against the un-irradiated counts. Residual foci were calculated as the percentage of foci remaining after 24 hours against the foci counted at 30 minutes post-irradiation. The bar graphs (A and B) show that the four control cell lines (MRC5VA, Empty-pFlag, pFlag-Ku70/wt, and pFlag-Ku80/ wt) displayed comparable levels of residual foci at 24 hours post-irradiation, on average $7 \%$, whereas the aceto-blocking (pFlag-Ku70-K317R, pFlagKu70-K331R and pFlag-Ku70-K338R) and aceto-mimicking (pFlag-Ku70-K317Q, pFlag-Ku70-K331Q and pFlag-Ku70-K338Q) mutant cell lines displayed a much higher amount of residual foci at 24 hours post-irradiation; with averages of 18 and $19 \%$ respectively. The experiment was repeated twice and the data was statistically analysed using Students' two-tailed t-test. 
Control cell lines

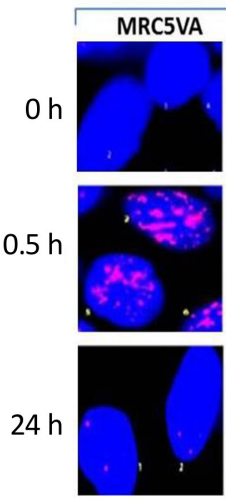

1
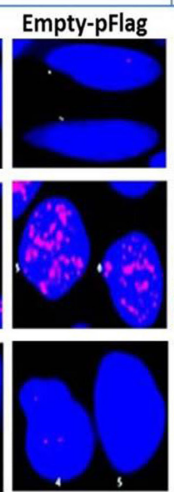

2
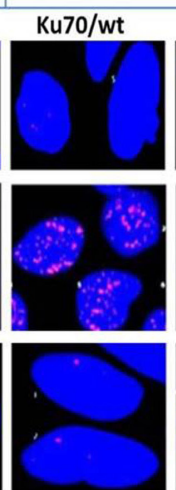

3
Ku70Lys<Arg Mutants

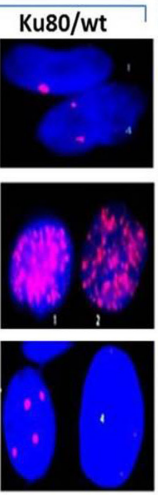

4
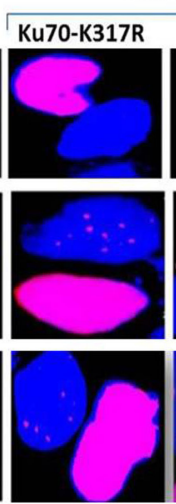

5

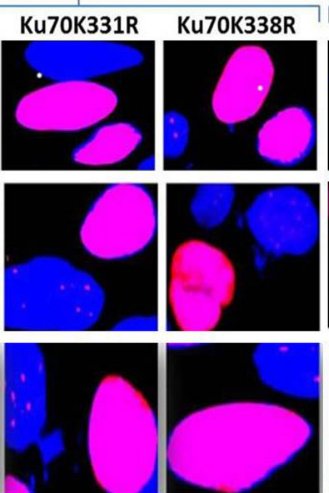

7

Ku70Lys $<$ Glu Mutants

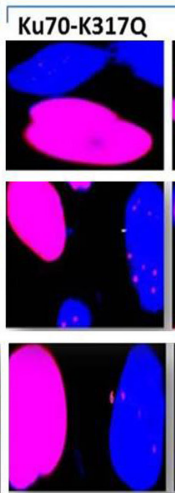

8

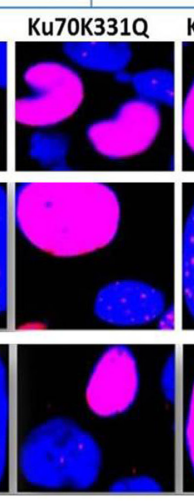

9
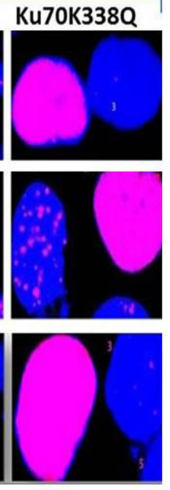

10

Figure 7. Pan-nuclear $\gamma \mathrm{H} 2 \mathrm{AX}$ staining of pFlag-Ku70 mutant cell lines. After $\gamma \mathrm{H} 2 \mathrm{AX}$ foci assay of all mutant and control cell lines were visualized by Carl Zeiss microscope with 100x objective and Smart Capture2 software, the images were processed by Adobe Photoshop Software. The control cells (MRC5VA, Empty-pFlag Vector, pFlag-Ku70/wt and pFlag-Ku80/wt; lanes 1, 2, 3 and 4 respectively) show foci staining pattern of $\gamma \mathrm{H} 2 \mathrm{AX}$ at all time points of irradiation ( 0 hour, 30 minutes and 24 hours post-irradiation), whereas pFlag-Ku70 aceto-blocking mutant pFlag-Ku70-K317R, pFlag-Ku70K331R and pFlag-Ku70-K338R cell lines (lanes 5, 6, and 7 respectively) and pFlag-Ku70 aceto-mimicking mutant pFlag-Ku70-K317Q, pFlag-Ku70K331Q and pFlag-Ku70-K338Q (lanes 8, 9, and 10 respectively) show a mix of characteristic pan-nuclear staining pattern and foci staining pattern of $\gamma \mathrm{H} 2 \mathrm{AX}$ at the same time points of irradiation. This pan-nuclear staining pattern may indicate a pre-apoptotic signal and the possibility that the acetylation and deacetylation of these lysine residues could be important for the apoptotic function previously reported for Ku70.

acetylation of $\mathrm{K} 317$ or K331 does not (although this work had not attempted to study the aceto-blocking effect at these lysine residues). In an attempt to explain the data mechanistically, their docking analysis suggests that both K317 and K331 residues pointed outward from the KU complex DNA-binding ring and, as such, should not be within effective range of electrostatic interactions with DNA [13]. These theoretical modeling assumptions were also questioned by a further study [27] which reported that K317 can be biotinylated in both free and DNA-bound KU. The examination of the crystal structure of KU-DNA complex revealed that the R-group of K317 is completely solvent-accessible for biotinylation. Nevertheless, they also found that the R-group of K331 which points into the central cavity where DNA is threading through the KU complex is always biotinylated when KU is free, but it is not accessible in KU bound to DNA. This indicates that the presence of DNA blocks chemical modification of this residue. These experimental results, unlike the theoretical docking analysis previously described, suggest that K331 located in the bridge-pillar region of Ku70 is in close proximity of the bound DNA. Interestingly, these authors also showed that for K338, which was reported to make contact with the DNA backbone in the crystal structure [16], the biotinylation was variable for both free and DNA-bound KU complexes.

Our data and the published results (including the partial discrepancies between all findings) are plausibly explained by a working model which takes into account the dynamic nature of KU-DNA binding. This dynamic nature suggests that the KU complex undergoes multiple conformational changes that accompany DNA binding and facilitates its role in DSBs repair [27]. This is consistent with the model where at least two of the three lysine residues (K331 and K338) of the KU-DNA-binding domain sequentially make contact with the DNA backbone during the inward movement of the KU complex along the DNA. We have previously shown that freedom to move inward on DNA is essential to KU stimulation of the LigIV/Xrcc4 complex [28], although the nature of the movement had not been fully investigated [29]. Assuming that KU inward movement on broken ends is rotational or oscillatory, all three lysine residues could sequentially approach the DNA backbone either directly contacting it or entering into the effective range of electrostatic interactions with the DNA backbone. Within this effective electrostatic range, DNA would sterically block lysine modifications. Moreover, the rotational movement can bring the lysine residues in the DNA-binding ring into the effective range of electrostatic interactions with DNA, forcing them inward towards the DNA backbone. With continued KU rotation, which may depend on the structure of the DNA break, this process can be reversed and a lysine which moved inward and contacted the DNA backbone might move outwards again and become accessible for another type of post translational modification (PTM). This would provide a docking site for different interacting proteins mediating post-kinase processes, including the binding of other NHEJ components and/or release of the KU complex and DNA-PKcs from the termini prior to ligation. The permanent presence of both aceto-mimicking and aceto-blocking modifications would very likely disrupt these processes, and this possibility is supported by the radiosensitivity phenotype of the mutants described in this study. To support and understand 
the implications of this model, we modeled possible interactions of these three lysine residues with the DNA substrate and the possible structural effects of aceto-mimicing and aceto-blocking mutants on KU-DNA dynamic interactions (Figure 8). K331 and K338 point directly towards the DNA backbone, implying that they are most likely involved in ionic salt bridge interactions with the negatively charged phosphates. Acetylation of these two residues or their mutational change to glutamine (Figure $8 \mathrm{C}$ ) would remove the charge interaction.

Although a hydrogen bond part of the salt bridge interaction would still be possible, the loss of the electrostatic interactions would significantly weaken the interaction between the KU complex and DNA. In contrast, mutating to arginine (Figure $8 \mathrm{~B}$ ) retains the charge-charge interaction (or even strengthens it), but this would then lose the ability to be acetylated and make it harder to dissociate from DNA when required after the completion of the repair reaction. Although K317 does not appear to be in close contact with DNA, our data shows a very similar functional mutational impact on the phenotype. One possibility already discussed earlier in the text is that the orientation of KU complex changes in such a way that different faces of the protein come in contact with DNA depending on the underlying PTMs of the critical interacting residues. A further option is that K317 could form a salt bridge with Glutamate 330 (E330). This salt bridge would then hold the helix containing both K331 and K338 in the optimum position to interact with DNA. Acetylation of K317 would result in loss of the salt bridge which could cause the movement of the helix away from this optimum position and therefore weaken the interaction. Consequently, its mutation to glutamine would mean that binding to DNA would be permanently compromised whereas mutating K317 to arginine would likely strengthen the salt bridge. This would either result in locking the helix in a suboptimal binding conformation (as the salt bridge formed by Glu-Arg may be subtly different from that of Glu-Gln) and thus resulting in weaker DNA binding, or locking the helix permanently in the perfect DNA binding position and compromising the dissociation from DNA triggered by acetylation in the wild type. This model also brings the attractive and simpler option that K317acetylation would weaken the lock of the complex on DNA which in turn could control sliding of the KU complex along the DNA away from DNA end, and provide the ability essential for the ligation step stimulation [28].

Taken together, the work undertaken here has provided evidence that maintaining the dynamic equilibrium of acetylation of the K317, $\mathrm{K} 331$ and $\mathrm{K} 338 \mathrm{Ku} 70$ lysine residues is critical for its function in DSBs repair. The results also suggest the possibility that other related regulatory PTMs of these residues might play a role, because the radiosensitisation seen in our study may be due to abolition of other PTMs that could otherwise take place on these residues. Future studies should address the question of how these residues impact on all previously identified Ku70 functional activities.
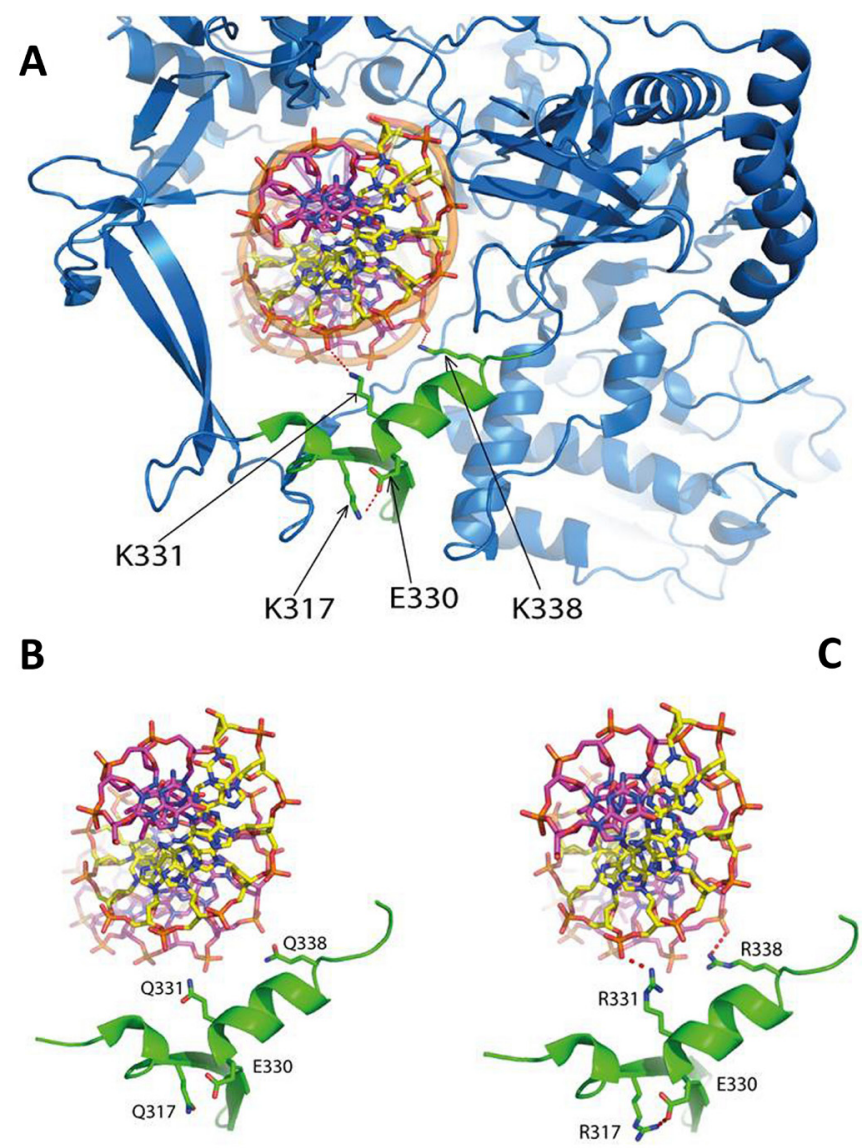

Figure 8. Structural modeling of the interactions of the three critical lysine residues with DNA and the impact of aceto-blocking and acetomimicking mutants on KU-DNA interactions. Modeling was performed using PyMOL and the pdb structure of KU heterodimer bound to DNA (1JEY) was used as the template. Mutants were simulated in PyMOL and the rotamer with the least energy was chosen for depiction. Ionic interactions were predicted based on inter-atom distances. Panel (A) shows a cartoon representation of the structure of $\mathrm{KU}$ heterodimer bound to DNA with the area of interest highlighted in green. The side-chains of key protein residues (Ku70-K317, Ku70-K331 and Ku70-K338) and DNA are shown in stick format. Key ionic interactions between Ku70-K331 and Ku70-K338 and the phosphodiester DNA backbone are shown with thin dashed red lines. In the wild type protein, Ku70-K331 and Ku70-K338 point towards DNA backbone implying that they are likely to interact with the negatively charged phosphate groups. Although not in direct contact with DNA backbone, Ku70-K317 has the ability to form salt bridge with glutamate $\mathrm{E} 330$ (Ku70-E330), optimising the position of the helix containing K331 and K338 for interaction with DNA. Acetylation of $\mathrm{K} 317$, which is reversible, results in loss of the salt bridge and possibly pushing the helix away from its optimal position, thus weakening KU-DNA interaction. In contrast, its mutation to glutamine (mimicking acetylation) means that binding to DNA would be permanently compromised and its mutation to arginine (mimicking deacetylation) would likely strengthen the salt bridge due to permanently locking the helix in either suboptimal or perfect DNA binding position thus compromising the dissociation from DNA triggered by acetylation in the wild type. Panel (B) shows that mutating all these residues to glutamine $(\mathrm{Ku} 70-\mathrm{K} 317 \mathrm{Q}$, $\mathrm{Ku} 70-\mathrm{K} 331 \mathrm{Q}$ and $\mathrm{Ku} 70-\mathrm{K} 338 \mathrm{Q})$ to mimic acetylation would render these ionic interactions no longer possible, whereas Panel C) shows that mutating to arginine (Ku70-K317Q, Ku70-K331Q and Ku70-K338Q) to mimic deacetylation would strengthen the charge-charge interactions; possibly resulting in losing the ability to dissociate from DNA. This is indicated by the thin dashed red lines. 
In conclusion, the data presented here, in the context of the present state of our knowledge of the importance of maintaining the acetylation equilibrium in cells highlights the need for more extensive studies to dissect the roles of acetylation/deacetylation mediated regulation of DNA repair pathways. Such studies have the potential to facilitate the design of new biological cancer therapies to complement standard chemotherapy and radiotherapy and improve the therapeutic outcomes for cancer patients.

\section{References}

[1] CHOU CH, WANG J, KNUTH MW, REEVES WH. Role of a major autoepitope in forming the DNA binding site of the p70 (Ku) antigen. J Exp Med 1992; 175: 1677-1684.

[2] WANG J, DONG X, MYUNG K, HENDRICKSON EA, REEVES WH. Identification of two domains of the p70 Ku protein mediating dimerization with $\mathrm{p} 80$ and DNA binding. J Biol Chem 1998; 273: 842-848.

[3] WANG J, DONG X, REEVES WH. A model for Ku heterodimer assembly and interaction with DNA. Implications for the function of Ku antigen. J Biol Chem 1998; 273: 31068-31074.

[4] WU X, LIEBER MR. Protein-protein and protein-DNA interaction regions within the DNA end-binding protein Ku70-Ku86. Mol Cell Biol 1996; 16: 5186-5193.

[5] COHEN HY, LAVU S, BITTERMAN KJ, HEKKING B, IMAHIYEROBO TA et al. Acetylation of the $\mathrm{C}$ terminus of $\mathrm{Ku} 70$ by CBP and PCAF controls Bax-mediated apoptosis. Mol Cell 2004; 13: 627-638.

[6] COHEN HY, MILLER C, BITTERMAN KJ, WALL NR, HEKKING B et al. Calorie restriction promotes mammalian cell survival by inducing the SIRT1 deacetylase. Science 2004, 305: 390-392. https://doi.org/10.1126/science.1099196

[7] SUBRAMANIAN C, OPIPARI AWJr, BIAN X, CASTLE VP, KWOK RP. Ku70 acetylation mediates neuroblastoma cell death induced by histone deacetylase inhibitors. Proc Natl Acad Sci U S A 2005; 102: 4842-4847. https://doi. org/10.1073/pnas.0408351102

[8] KOUZARIDES T. Histone acetylases and deacetylases in cell proliferation. Curr Opin Genet Dev 1999; 9: 40-48.

[9] BIG,JIANGG. The molecular mechanism of HDACinhibitors in anticancer effects. Cell Mol Immunol 2006; 3: 285-2890.

[10] BROWN R, STRATHDEE G. Epigenomics and epigenetic therapy of cancer. Trends Mol Med 2002; 8: S43-48.

[11] LIN HY, CHEN CS, LIN SP, WENG JR, CHEN CS. Targeting histone deacetylase in cancer therapy. Med Res Rev 2006; 26: 397-413. https://doi.org/10.1002/med.20056

[12] CHEN CS, WENG SC, TSENG PH, LIN HP, CHEN CS. Histone acetylation-independent effect of histone deacetylase inhibitors on Akt through the reshuffling of protein phosphatase 1 complexes. J Biol Chem 2005; 280: 38879-3887. https://doi.org/10.1074/jbc.M505733200

[13] CHEN CS, WANG YC, YANG HC, HUANG PH, KULP SK et al. Histone deacetylase inhibitors sensitize prostate cancer cells to agents that produce DNA double-strand breaks by targeting Ku70 acetylation. Cancer Res 2007; 67: 5318-5327. https://doi.org/10.1158/0008-5472.CAN-06-3996
[14] WALKER JR, CORPINA RA, GOLDBERG J. Structure of the $\mathrm{Ku}$ heterodimer bound to DNA and its implications for double-strand break repair. Nature 2001; 412: 607-614. https:// doi.org/10.1038/35088000

[15] ZHANG Y, ADACHI M, ZOU H, HAREYAMA M, IMAI K et al. Histone deacetylase inhibitors enhance phosphorylation of histone $\mathrm{H} 2 \mathrm{AX}$ after ionizing radiation. Int J Radiat Oncol Biol Phys 2006; 65: 859-866. https://doi.org/10.1016/j. ijrobp.2006.03.019

[16] CHEN LA, ANKER CJ, HUNT JP, BUCHMANN LO, GROSSMANN KF et al. Clinical outcomes associated with evolving treatment modalities and radiation techniques for base-of-tongue carcinoma: thirty years of institutional experience. Cancer Med 2015; 4: 651-660. https://doi. org/10.1002/cam4.364

[17] LAWRENCE T, HAFFTY B, HARRIS J. Milestones in the Use of Combined-Modality Radiation Therapy and Chemotherapy. J Clin Oncol 2014; 2: 1173-1179. https://doi. org/10.1200/JCO.2014.55.2281

[18] DELANO WL. The PyMOL Molecular Graphics System, Version 1.8 Schrödinger, LLC; 2002.

[19] LI M, LUO J, BROOKS CL, GU W. Acetylation of p53 inhibits its ubiquitination by Mdm2. J Biol Chem 2002; 277: 50607-50611. doi:10.1074/jbc.C200578200

[20] ROGAKOU EP, NIEVES-NEIRA W, BOON C, POMMIER Y, BONNER WM. Initiation of DNA Fragmentation during Apoptosis Induces Phosphorylation of H2AX Histone at Serine 139. J Biol Chem 2000; 275: 9390-9395.

[21] ROGAKOU EP, PILCHDR DR, ORR AH, IVANOVA VS, BONNER WM. DNA double-stranded breaks induce histone H2AX phosphorylation on serine 139. J Biol Chem 1998; 273: 5858-5868.

[22] BANATH JP, MACPHAIL SH, OLIVE PL. Radiation Sensitivity, H2AX Phosphorylation, and Kinetics of Repair of DNA Strand Breaks in Irradiated Cervical Cancer Cell Lines. Cancer Res 2004; 64: 7144-7149. https://doi.org/10.1158/00085472.CAN-04-1433

[23] SEDELNIKOVA OA1, PILCH DR, REDON C, BONNER WM. Histone $\mathrm{H} 2 \mathrm{AX}$ in DNA damage and repair. Cancer Biol Ther 2003; 2: 233-235.

[24] KLOKOV D, MACPHAIL SM, BANATH JP, BYRNE JP, OLIVE PL. Phosphorylated histone $\mathrm{H} 2 \mathrm{AX}$ in relation to cell survival in tumor cells and xenografts exposed to single and fractionated doses of X-rays. Radiother Oncol 2006; 80: 223-229. https://doi.org/10.1016/j.radonc.2006.07.026

[25] GIRARD PM, KYSELA B, HaARER CJ, DOHERTY AJ, JEGGO PA. Analysis of DNA ligase IV mutations found in LIG4 syndrome patients: the impact of two linked polymorphisms. Hum Mol Genet 2004; 13: 2369-2376. https://doi. org/10.1093/hmg/ddh274

[26] RIBALLO E, DOHERTY AJ, DAI Y, STIFF T, OETTINGER MA et al. Cellular and biochemical impact of a mutation in DNA ligase IV conferring clinical radiosensitivity. J Biol Chem 2001; 276: 31124-31132. https://doi.org/10.1074/jbc. M103866200

[27] LEHMAN JA, HOELZ DJ, TURCHI JJ. DNA-dependent conformational changes in the Ku heterodimer. Biochemistry 2008; 47: 4359-4368. https://doi.org/10.1021/bi702284c 
[28] KYSELA B, DOHERTY AJ, CHOVANEC M, STIFF T, AMEER-BEG SM et al. Ku stimulation of DNA ligase IV-dependent ligation requires inward movement along the DNA molecule. J. Biol Chem 2003; 278: 22466-22474. https://doi. org/10.1074/jbc.M303273200
[29] MARI PO, FLOREA BI, PERSENGIEV SP, VERKAIK NS, BRÜGGENWIRTH HT et al. Dynamic assembly of endjoining complexes requires interaction between Ku70/80 and XRCC4. Proc Natl Acad Sci U S A 2006; 103: 18597-18602. https://doi.org/10.1073/pnas.0609061103 